\title{
Direct Vasoconstriction as a Possible Cause for Amphotericin B-induced Nephrotoxicity in Rats
}

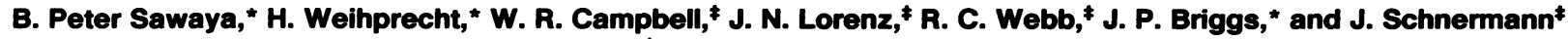 \\ Departments of Internal Medicine* and Physiology, ${ }^{\ddagger}$ University of Michigan, Ann Arbor, Michigan 48109
}

\begin{abstract}
In anesthetized rats we tested the hypothesis that amphotericin B (AmB) reduces glomerular filtration rate (GFR) by activating the tubuloglomerular feedback (TGF) mechanism. Infusion of $1 \mathrm{mg} / \mathrm{kg} \mathrm{AmB}$ over $50 \mathrm{~min}$ was followed by a reduction in kidney GFR (from $0.47 \pm 0.03$ to $0.39 \pm 0.02 \mathrm{ml} / \mathrm{min}$ per $100 \mathrm{~g}$ body wt during the second hour after infusion; $P<0.05$ ) and by an increase in urine flow and urinary chloride excretion. Singlenephron GFR (SNGFR) measured in proximal (TGF interrupted) or distal tubules (TGF intact) decreased to a similar degree from $33.4 \pm 1.8$ and $30.6 \pm 1.2 \mathrm{nl} / \mathrm{min}$ in the control period to $19.7 \pm 1.9$ and $21.2 \pm 1.6 \mathrm{nl} / \mathrm{min}$ during the second hour after AmB infusion $(P<0.05)$. Distal chloride concentrations and TGF responses to changes in loop of Henle flow rate were not significantly altered by $\mathrm{AmB}$. AmB at $10^{-5} \mathrm{M}$ reduced the diameter of isolated perfused afferent arterioles from rabbit kidneys. In isometrically contracting rings of rabbit aorta and renal artery in vitro AmB produced endothelium-independent constriction, with half-maximal contraction $\left(\mathbf{E C}_{50}\right)$ being achieved by $1.8 \times 10^{-6}$ and $2.6 \times 10^{-6} \mathrm{M}$ in intact vessels and $1.3 \times 10^{-6}$ and $1.7 \times 10^{-6} \mathrm{M}$ in endothelium-denuded ressels respectively. Tension development did not occur in Ca-free media or in the presence of $\mathrm{Ca}$ channel blockers. Pretreatment with ouabain or Bay $\mathrm{K} 8644$ potentiated the effect of AmB. The vasoconstrictive effect of AmB was counteracted by aminophylline and atrial natriuretic peptide. We conclude that the AmBinduced reduction in GFR is not caused by TGF activation and that AmB has a direct vasoconstrictor effect that is probably initiated by depolarization-induced opening of $\mathrm{Ca}$ channels. This effect may be an important component of the nephrotoxic actions of AmB. (J. Clin. Invest. 1991. 87:2097-2107.) Key words: afferent arteriole $\bullet$ aminophylline $\bullet$ micropuncture $\bullet$ rabbit aorta • tubuloglomerular feedback • verapamil
\end{abstract}

\section{Introduction}

The polyene antibiotic amphotericin $B(A m B)^{1}$ is used extensively in the treatment of systemic fungal infections. Soon after

This study was presented in part at the 22nd Annual Meeting of the American Society of Nephrology, Washington, DC 1989 and at the FASEB Meeting, Washington, DC 1990.

Address reprint requests to Dr. Schnermann, Department of Physiology, Medical Science Building II, No. 7712, University of Michigan, Ann Arbor, MI 48109.

Received for publication 18 June 1990 and in revised form 29 January 1991.

1. Abbreviations used in this paper: AmB, amphotericin B; BW, body weight; PSS, physiological salt solution; TGF, tubuloglomerular feedback.

J. Clin. Invest.

(C) The American Society for Clinical Investigation, Inc.

$0021-9738 / 91 / 06 / 2097 / 11 \quad \$ 2.00$

Volume 87, June 1991, 2097-2107 its introduction as a therapeutic agent in 1956, it was recognized that a high incidence of nephrotoxic side effects can substantially limit its clinical usefulness $(1,2)$. In addition to signs of tubular dysfunction such as a distal tubular acidification defect (3-5), AmB administration often produces a reduction in renal blood flow and glomerular filtration rate (GFR) (6-8). The absence of marked structural alterations (9) and the dissociation between azotemia and morphologic changes (10) have suggested a functional pathogenesis of AmB-induced renal failure.

It has been proposed that $\mathrm{AmB}$ increases renal vascular resistance by activating the tubuloglomerular feedback (TGF) mechanism (11). Increases in $\mathrm{NaCl}$ concentration at the macula densa augment the tone of glomerular arterioles, specifically at preglomerular sites (12). Since AmB can alter ion fluxes in both artificial and biological membranes $(13,14)$, it seemed possible that AmB may increase salt concentrations at the macula densa and thus produce TGF-dependent vasoconstriction. Apparent support for this proposal came from observations that interventions known to block or attenuate the TGF mechanism ameliorate AmB-induced nephrotoxicity. These maneuvers include salt loading $(11,15)$ and pretreatment with furosemide $(11,16)$, aminophylline (17-19), or verapamil $(8,20)$.

The first aim of the present study was to directly test the role of the TGF mechanism in AmB-induced reductions of GFR. The following specific questions were addressed: $(a)$ Is the fall in single-nephron GFR (SNGFR) caused by AmB dependent upon delivery of tubular fluid to the macula densa; $(b)$ does AmB generate a signal for vascular constriction by increasing distal $\mathrm{NaCl}$ concentration; and $(c)$ is the sensitivity of the TGF response to a known tubular signal abnormal?

These studies did not support the contention that the TGF mechanism contributes importantly to AmB-induced renal vasoconstriction. We therefore performed a second series of experiments in which we investigated a possible direct vasoconstrictor action of AmB in perfused afferent arterioles and isometrically contracting rings of rabbit aorta and renal artery. Our results show that $\mathrm{AmB}$ can produce vasoconstriction in vitro and thus are compatible with the notion that the renovascular effects of AmB may result at least in part from a direct effect of AmB on vascular smooth muscle cells.

\section{Methods}

\section{Effect of $A m B$ on renal function in rats}

Studies were done in 41 male Sprague-Dawley rats (250-350g) anesthetized by an intraperitoneal injection of $120 \mathrm{mg} / \mathrm{kg}$ thiobutabarbital (Inactin, Byk-Gulden, Constance, FRG). Catheters were placed in the left femoral artery for blood pressure monitoring and collection of blood samples, and in the left jugular vein for infusions of fluids and drugs. Catheters were also inserted into the trachea and ureters. Rats were placed on a heated table that maintains core temperature at $37^{\circ} \mathrm{C}$. Upon completion of surgery, a waiting period of $1 \mathrm{~h}$ was allowed for equilibration. During the first hour of the experiment control measurements were made. AmB (Fungizone, lot no. 43730, E. R. Squibb \& 
Sons, Inc., Princeton, NJ) was then given as an intravenous infusion of $1 \mathrm{mg} / \mathrm{kg}$ over $50 \mathrm{~min}$. AmB was freshly prepared for each experiment as an aqueous $5 \mathrm{mg} / \mathrm{ml}$ solution. For infusion the amount required $(0.05-$ $0.07 \mathrm{ml}$ ) was diluted in the infusion volume of $0.5 \mathrm{ml}$ saline. All solutions were visually clear with no evidence of precipitation.

Inulin recovery. The effect of $\mathrm{AmB}$ on inulin recovery was examined in 13 rats receiving an infusion of $0.9 \% \mathrm{NaCl}$ at the relatively high rate of $1 \mathrm{ml} / 100 \mathrm{~g}$ of body $\mathrm{wt}(\mathrm{BW}) \mathrm{h}^{-1}$ in order to increase urine flow rate. The left kidney was placed in a lucite cup and the kidney was covered with mineral oil. To determine inulin recovery, between 20 and 40-nl droplets of a stained Ringer solution containing fresh $\left[{ }^{3} \mathrm{H}\right]-$ inulin (ICN Radiochemicals, Irvine, CA; purity $>95 \%$ ) at a concentration of $50 \mu \mathrm{Ci} / \mathrm{ml}$ were aspirated into mineral oil-filled micropuncture pipettes (tip diam $5 \mu \mathrm{m}$ ). The tip of the pipette was sealed with a small drop of stained castor oil. The pipette content was injected into proximal tubules over 1-3 min. Urine from both kidneys was collected separately in tared tubes in 30-min intervals. Radioactivity in urine and in triplicates of the injectate were counted in a liquid scintillation counter. A total of 9 control and 30 post-AmB microinjections were performed. Injections were not accepted as satisfactory if there was indication of upstream or unusually slow flow or of extraluminal deposition of some of the injectate. Microinjections were performed before AmB administration, at the end of the infusion period, and at hourly intervals thereafter for up to $4 \mathrm{~h}$.

Clearance experiments. This group consisted of 11 rats given AmB and 5 control rats receiving vehicle alone $(0.82 \mathrm{mg} / \mathrm{kg} \mathrm{Na}$ deoxycholate). The left kidney was placed in a lucite cup and the left ureter was cannulated. Rats were infused with $4 \mathrm{~g} \%$ albumin in $0.9 \% \mathrm{NaCl}$ at a rate of $0.6 \mathrm{ml} / 100 \mathrm{~g} \mathrm{BW} \mathrm{h}^{-1}$ for $45 \mathrm{~min}$ during surgery followed by $1 \mathrm{~g} \%$ albumin in saline at the same rate for the rest of the experiment. ${ }^{3} \mathrm{H}$-labeled inulin was given as a bolus $(4 \mu \mathrm{Ci})$ followed by an infusion of 4.5 $\mu \mathrm{Ci} / 100 \mathrm{~g} \mathrm{BW} \mathrm{h}^{-1}$. After $30 \mathrm{~min}$ of equilibration, a control period of 60 min was begun in which $35 \mu \mathrm{l}$ of blood was collected at 30-min intervals. AmB infusion was then started and additional blood samples were taken every $45 \mathrm{~min}$. Urine was collected for 20 -min periods throughout the experiment. $\left[{ }^{3} \mathrm{H}\right]$ Inulin was determined in plasma and urine samples by liquid scintillation counting.

Single-nephron studies. Micropuncture studies were performed in five rats infused with $0.9 \% \mathrm{NaCl}$ at a rate of $0.6 \mathrm{ml} / 100 \mathrm{~g} \mathrm{BW} \mathrm{h}^{-1}$. No albumin was given in order to maintain the animals in a hydropenic state which may enhance the susceptibility to the vascular effects of AmB (11). The left kidney was prepared as above. After completion of surgery and a waiting period of $45 \mathrm{~min}\left[{ }^{3} \mathrm{H}\right]$ inulin was given as a bolus $(40 \mu \mathrm{Ci})$ followed by an infusion of $45 \mu \mathrm{Ci} / 100 \mathrm{~g} \mathrm{BW} \mathrm{h}^{-1}$.

Timed fluid collections were made in distal and end-proximal segments of the same nephron, identified by dye injections from a 5- $\mu \mathrm{m}$ tipped pipette that was connected to a manometer and was also used to control intratubular pressure during the collections. Collection times were between 2.5 and $4.5 \mathrm{~min}$. In general, three sample pairs were collected during the control period, two pairs in the second half of the AmB infusion period and additional pairs in the first and second hour after AmB infusion. Plasma and urine samples were collected as described for clearance experiments. Tubular fluid volume was measured in a constant bore capillary. A portion of the sample was used for $\mathrm{Cl}$ determinations with an electrometric microtitrator (World Precision Instruments, Inc., New Haven, CT). The volume of the remaining sample was again measured and transferred into a scintillation vial for radioactivity counting. Urinary $\mathrm{Cl}$ was measured with a digital chloridometer (Haake Buchler Instruments, Inc., Saddle Brook, NJ).

Sensitivity of TGF mechanism. In four rats, TGF sensitivity was studied by measuring stop flow pressure $\left(P_{\mathrm{SF}}\right)$ responses to changes in loop of Henle perfusion rate before, during, and after AmB administration. Surgery and fluid replacement protocols were identical to that in the micropuncture group. As described previously (21), $P_{\mathrm{SF}}$ was measured with a servo-null pressure device (World Precision Instruments) during perfusion of loops of Henle at $0,10,20$, and $45 \mathrm{nl} / \mathrm{min}$ with a Ringer solution containing (in mM): $136 \mathrm{NaCl}, 4 \mathrm{NaHCO}_{3}, 4 \mathrm{KCl}, 2$ $\mathrm{CaCl}_{2}, 7.5$ urea, and $100 \mathrm{mg} / 100 \mathrm{ml}$ FD\&C Green. Measurements of
$P_{\mathrm{SF}}$ responses were made during the control period, during the last 20 min of the AmB infusion period, and during the first $2 \mathrm{~h}$ after AmB infusion. The relationship between $P_{\mathrm{SF}}$ and flow rate (21) was evaluated by determining feedback curve parameters $(k$, an exponential constant; $V_{1 / 2}$, the flow at which the response is half-maximum; $P_{\mathrm{SFmax}}$, the maximum decrease of $P_{\mathrm{SF}}$ ) from the experimental data using a quasiNewton iterative least squares curve-fitting procedure (Systat, Evanston, IL).

Effect of peritubular infusion on $P_{S F}$. To test the effect of $\mathrm{AmB}$ on renal microvessels in vivo without the complicating effects of systemic administration, $P_{\mathrm{SF}}$ was measured in six nephrons in two rats during peritubular infusions of AmB. The loop of Henle was not perfused in these experiments. Rats were prepared for micropuncture as described above. $P_{\mathrm{SF}}$ was measured before, during, and after infusion of $10^{-4} \mathrm{M}$ $\mathrm{AmB}$ in Ringer solution at $30 \mathrm{nl} / \mathrm{min}$ into prominent peritubular capillaries adjacent to the nephron under study. In additional experiments we tested the effect of peritubular infusion of a Ringer solution containing solvent alone $\left(10^{-4} \mathrm{M} \mathrm{Na}\right.$ deoxycholate).

$A m B$ serum level. In four rats $250-\mu \mathrm{l}$ blood samples were taken at the end of the AmB infusion, and 30 and 90 min thereafter for the determination of AmB levels. Serum was separated and stored frozen and protected from light until being sent for AmB determinations. Serum AmB levels were assessed by the National Reference Laboratory, Inc., Kirksville, MO, using a standard bioassay method that measures biologically active levels of AmB.

\section{Effect of AmB on isolated vessels of rabbits}

Afferent arterioles. Afferent arterioles of rabbit kidneys were dissected from slices of left kidneys of New Zealand white rabbits $(800-1,500 \mathrm{~g})$. Dissection was done at $4^{\circ} \mathrm{C}$ under a stereo dissection microscope (Bausch and Lomb, Inc., Rochester, NY, $\times 10-70$ ). After selecting an afferent arteriole from the outer cortex tubular fragments were carefully removed using sharpened forceps. Care was taken not to stretch the vessels or to touch the vascular structures at the glomerular hilum. After dissection the interlobular artery was cut with a razor blade piece about $100 \mu \mathrm{m}$ proximal and $100-200 \mu \mathrm{m}$ distal to the arteriolar branchpoint. The dissected specimens consisting of a segment of interlobular artery, the afferent arteriole, the glomerulus, and a fragment of the efferent arteriole were transferred to a thermoregulated bath placed on the stage of an inverted microscope (model IMT-2, Olympus Corp. of America, New Hyde Park, NY). The afferent arteriole was cannulated by advancing a perfusion pipette through the lumen of the interlobular artery using concentric pipettes mounted on a moveable track system identical to that used for tubule perfusions (22). The perfusate was driven by a hydraulic pressure of $110 \mathrm{~cm} \mathrm{H}_{2} \mathrm{O}$. After establishing vessel perfusion the bath temperature was elevated to $38^{\circ} \mathrm{C}$. Fresh bath medium was supplied at a rate of $0.2 \mathrm{ml} / \mathrm{min}$ and removed by carefully collecting the accumulating bath fluid in 5-min intervals. In most vessels spontaneous contractions with varying intensity were observed in the warmup period which subsided during the waiting period of $30-40$ $\mathrm{min}$. Before studies were begun the specimen was inspected for cellular integrity using differential interference contrast optics (Olympus Corp. model IMT-2-DIC) at $\times 600$ and $\times 1,000$.

Dissection and bath media were prepared from Dulbecco's modified Eagle's medium (DME mixture F 12, Sigma Chemical Co., St. Louis, MO) with the addition of $1.2 \mathrm{~g} / 1$ of $\mathrm{NaHCO}_{3}$. Before use this solution was aerated with $95 \% \mathrm{O}_{2} / 5 \% \mathrm{CO}_{2}$ for $45 \mathrm{~min}$ and its $\mathrm{pH}$ was adjusted to 7.4. When used as dissection medium 3\% fetal calf serum was added (Gibco Laboratories, Grand Island, NY). When used as bath medium $5 \mathrm{~g} / 100 \mathrm{ml}$ human serum albumin (Sigma Chemical Co.) was added instead. Vessel perfusion fluid was a modified Krebs-Ringer$\mathrm{HCO}_{3}$ buffer containing (in mM): $115 \mathrm{NaCl}, 25 \mathrm{NaHCO}_{3}, 0.96$ $\mathrm{NaH}_{2} \mathrm{PO}_{4}, 0.24 \mathrm{Na}_{2} \mathrm{HPO}_{4}, 5 \mathrm{KCl}, 1.2 \mathrm{MgSO}_{4}, 2 \mathrm{CaCl}_{2}, 5.5$ glucose, and $1 \mathrm{~g} / 100 \mathrm{ml}$ bovine serum albumin. The buffer was bubbled with $95 \% \mathrm{O}_{2} / 5 \% \mathrm{CO}_{2}$ and $\mathrm{pH}$ adjusted to 7.4. After a waiting period of about 30 min control measurements were made. $\mathrm{AmB}\left(5 \times 10^{-5} \mathrm{M}\right)$ was then added to the bath and effects were observed for $10 \mathrm{~min}$. In some vessels $\mathrm{AmB}$ was given together with $10^{-5} \mathrm{M}$ nifedipine. 
Experiments were videotaped at $\times 600$ or $\times 1,000$ using differential interference contrast optics. Using an image analysis system (CUE 2, Olympus Corp.) vascular diameter changes were measured on the videoimages at $1,3,5$, and $10 \mathrm{~min}$ at two sites of the vessel representing locations of maximum and minimum responsiveness to AmB.

Isolated rings of aorta and renal artery. Blood vessels were harvested from the same rabbits used as donors for the arteriolar perfusion experiments. Pieces of the abdominal aorta and right renal artery were excised, transferred into physiological salt solution (PSS), cleaned of fat and connective tissue, and cut into 3-mm segments. Connected to model FT .03 force transducers (Grass Instrument Co., Quincy, MA) vessel rings were suspended in glass chambers containing $40 \mathrm{ml}$ PSS, and a passive force of $3,000 \mathrm{mg}$ for the abdominal aorta and $1,500 \mathrm{mg}$ for the renal artery was applied. Each chamber contained two strips, one intact and one with the endothelium removed by gentle rubbing. Vessels were allowed to equilibrate for $2 \mathrm{~h}$ in PSS at $37^{\circ} \mathrm{C}$. The composition of the bathing medium was as follows (mM): $\mathrm{NaCl} 130, \mathrm{KCl} 4.7$, $\mathrm{KH}_{2} \mathrm{PO}_{4} 1.18, \mathrm{MgSO}_{4} 1.17, \mathrm{CaCl}_{2} 1.6, \mathrm{NaHCO}_{3} 14.9$, dextrose 5.5, and CaNa-EDTA 0.03 ( $\mathrm{pH} 7.2-7.4$ ). After the equilibration period, all vessels were exposed twice to a depolarizing solution $(100 \mathrm{mM} \mathrm{KCl})$ which was used as reference point, to norepinephrine at $10^{-7} \mathrm{M}$ and to $10^{-6} \mathrm{M}$ acetylcholine to assure removal of the endothelium in the denuded vessels.

Drugs used were as follows: AmB (Squibb) dissolved in distilled water at a maximum concentration of $5 \times 10^{-3} \mathrm{M}$ and kept refrigerated and protected from light for a maximum of $1 \mathrm{wk}$; verapamil (Sigma Chemical Co.) dissolved in $100 \%$ alcohol (the final concentration of alcohol in the bath did not exceed 0.1\%); BAY K 8644 dissolved in $100 \%$ alcohol with final bath concentrations not exceeding $0.1 \%$ (courtesy of Bayer AG, Wuppertal, FRG); ouabain (Sigma Chemical Co.); aminophylline (Sigma Chemical Co.); atrial natriuretic peptide (Sigma Chemical Co.); phentolamine (CIBA Pharmaceutical Co., Summit, $\mathrm{NJ}$ ); and $\mathrm{Na}$ deoxycholate (Sigma Chemical Co.).

Statistical analysis. All results are expressed as means \pm SE. Statistical analysis was performed using either a single-factor analysis of variance (ANOVA) with repeated measures or a two-factor ANOVA with repeated measures on the second factor. Post-hoc comparisons using the Newman-Keuls multiple range test were used to supplement the ANOVA when necessary. Inulin recovery results were assessed using paired t-tests with missing data, as discussed in Snedecor and Cochran (23). The decision for statistical significance was made at $P<0.05$.

\section{Results}

\section{Effect of $A M B$ on renal function in rats}

Inulin recovery. The recovery of microinjected inulin in the urine averaged $104.2 \pm 3.1 \%(n=6)$ in control and $100.2 \pm 1.7 \%$ $(n=9)$ during AmB administration. A modest reduction to $91.7 \pm 2.1 \%(n=9 ; P<0.05)$ and $94.0 \pm 2.5 \%(n=9 ; P<0.05)$ was noted in the injected kidneys in the second and third hour after AmB infusion. However, since at the same time recovery was negligible in the contralateral kidneys, the importance of this finding is questionable. Inulin recovery was $95.8 \pm 2.8 \%$ ( $n$ $=9$; NS) in the fourth hour after AmB infusion.

Clearance experiments. The effect of AmB on inulin clearance $\left(C_{\mathrm{ln}}\right)$ was measured in 11 rats. In view of only minimal inulin loss, $C_{\mathrm{ln}}$ is taken as a measure of GFR. In the time control rats infused with the deoxycholate vehicle, $C_{\ln }$ declined slightly over $3 \mathrm{~h}$, but the change was not significant (Fig. $1 a$ ). In the AmB-infused rats, $C_{\ln }$ decreased in the second half of the $A m B$ infusion period in half of the treated rats, but the overall reduction of GFR during this period did not reach statistical significance (Fig. $1 a$ ). A significant reduction of $C_{\ln }$ was found in the period beginning $40 \mathrm{~min}$ after terminating $\mathrm{AmB}$ infusion. Mean GFR in that period was $0.39 \pm 0.02 \mathrm{ml} / 100 \mathrm{~g} \mathrm{BW}$

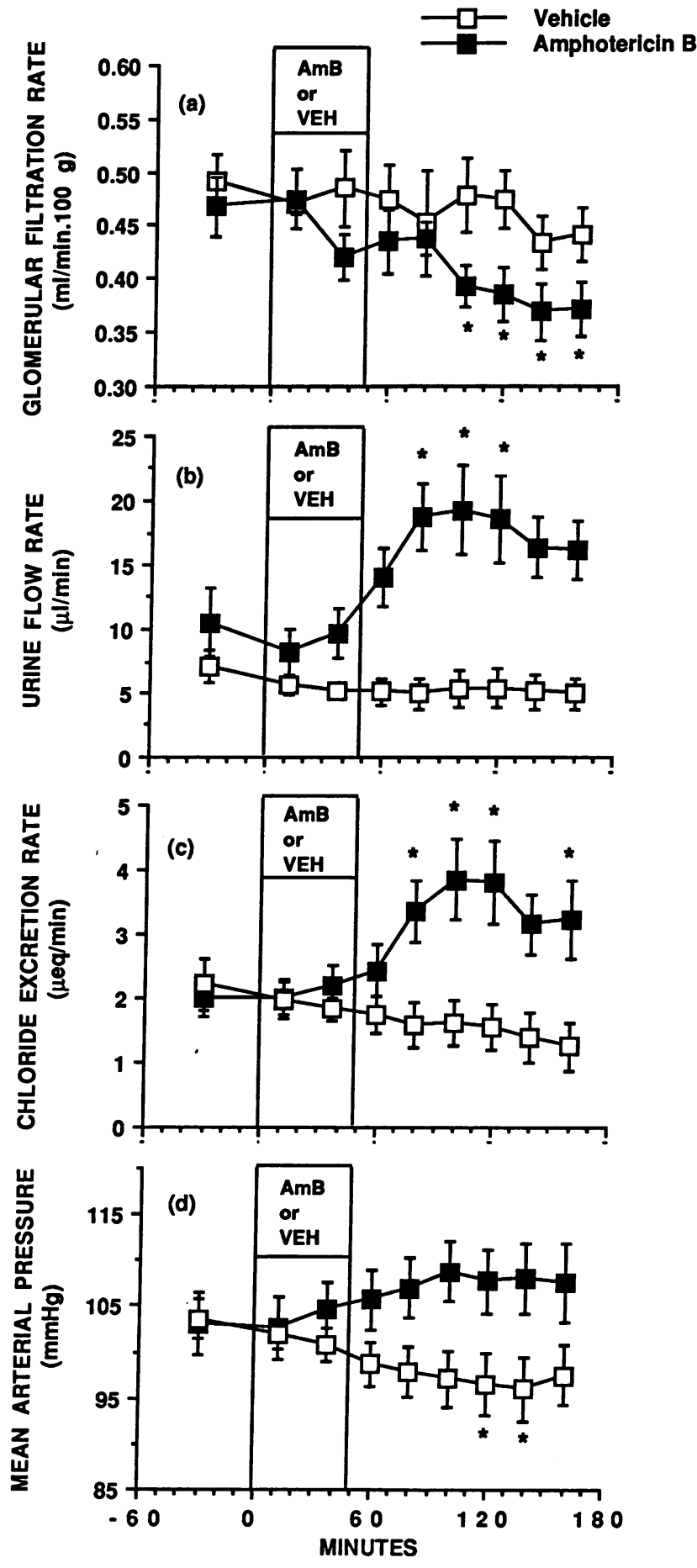

Figure 1. Effect of $\operatorname{AmB}(\square, n=11)$ or vehicle $(\square, n=5)$ infusion on (a) glomerular filtration rate, $(b)$ urine flow rate, $(c)$ chloride excretion, and $(d)$ mean arterial pressure in anesthetized rats. ${ }^{*} P<0.05$ vs. control.

per min, significantly lower than the mean of $0.47 \pm 0.03 \mathrm{ml} /$ $100 \mathrm{~g} \mathrm{BW}$ per min in the control period ( $P<0.05$, ANOVA). Significant reductions in $C_{\ln }$ were also seen in all later collection periods. In response to $\mathrm{AmB}$ infusion urine flow rate rose from a control value of $10.5 \pm 3.3 \mu \mathrm{l} / \mathrm{min}$ to a peak of $19.3 \pm 3.0$ $\mu \mathrm{l} / \mathrm{min} 40 \mathrm{~min}$ after the end of the infusion $(P<0.05)$ (Fig. $1 \mathrm{~b}$ ). Diuresis was associated with a modest decrease in urinary $\mathrm{Cl}$ 
Table I. Summary of Micropuncture Results

\begin{tabular}{|c|c|c|c|c|}
\hline & Control & During $(\% \Delta)$ & After 1 st $h(\% \Delta)$ & After 2 nd h $(\% \Delta)$ \\
\hline \multicolumn{5}{|l|}{ Glomerular filtration rate } \\
\hline$(\mathrm{ml} / 100 \mathrm{~g} \mathrm{BW} \cdot \mathrm{min})$ & $0.44 \pm 0.01$ & $0.34 \pm 0.03(23 \%)^{*}$ & $0.39 \pm 0.03(11 \%)$ & $0.35 \pm 0.03(20 \%)$ \\
\hline Proximal SNGFR $(\mathrm{nl} / \mathrm{min})$ & $33.4 \pm 1.8$ & $19.7 \pm 1.9(41 \%)^{*}$ & $30.4 \pm 2.4(9 \%)$ & $19.7 \pm 1.6(41 \%)^{*}$ \\
\hline Distal SNGFR (nl/min) & $30.6 \pm 1.2^{\ddagger}$ & $21.2 \pm 1.6(31 \%)^{*}$ & $26.9 \pm 2.0(12 \%)^{\ddagger}$ & $18.7 \pm 0.4(39 \%)^{*}$ \\
\hline$\Delta \operatorname{SNGFR}(n l / m i n)$ & $3.0 \pm 1.1$ & $-3.3 \pm 2.3$ & $3.5 \pm 2.1$ & $1.0 \pm 1.2$ \\
\hline Distal flow rate $(\mathrm{nl} / \mathrm{min})$ & $6.8 \pm 1.0$ & $4.9 \pm 1.0$ & $7.1 \pm 1.4$ & $4.9 \pm 0.6$ \\
\hline Distal [Cl] (meq/liter) & $49.1 \pm 13.4$ & $66.5 \pm 10.1$ & $61.5 \pm 4.1$ & $49.9 \pm 4.9$ \\
\hline Proximal-TF/P & $2.1 \pm 0.3$ & $2.5 \pm 0.3$ & $1.8 \pm 0.2$ & $1.8 \pm 0.2$ \\
\hline Distal-TF/P & $5.3 \pm 0.9$ & $5.2 \pm 0.8$ & $4.5 \pm 1.3$ & $4.4 \pm 0.7$ \\
\hline $\mathrm{P}-\% \mathrm{H}_{2} \mathrm{O}$ absorption & $48.8 \pm 5.5$ & $56.4 \pm 5.8$ & $43.0 \pm 6.5$ & $38.8 \pm 6.9$ \\
\hline D-\% $\mathrm{H}_{2} \mathrm{O}$ absorption & $79.1 \pm 2.4$ & $79.2 \pm 3.0$ & $72.8 \pm 4.9$ & $74.4 \pm 2.9$ \\
\hline n (rats/tubules) & $5 / 15$ & $4 / 4$ & $5 / 10$ & $3 / 6$ \\
\hline
\end{tabular}

Abbreviations: $\mathrm{P}$, proximal; D, distal; TF/P, tubular fluid/plasma inulin concentration. $\% \mathrm{H}_{2} \mathrm{O}$ absorption: proximal $=(1-1 / \mathrm{TF} / \mathrm{P}) \times 100 ;$ distal $=($ distal SNGFR - distal $\dot{\mathrm{V}} /$ distal SNGFR $) \times 100 .{ }^{*} P<0.05$ vs control; ${ }^{\ddagger} P<0.05$ distal vs. proximal.

concentration (control from $265.5 \pm 31.8$ to $201.5 \pm 16.5 \mathrm{mM}$ at the 40 -minute postinfusion time point; $P<0.05$ ). The resultant urinary $\mathrm{Cl}$ excretion rate increased significantly in the AmB-treated group from $2.0 \pm 0.27 \mu \mathrm{mol} / \mathrm{min}$ in the control period to $3.8 \pm 0.63 \mu \mathrm{mol} / \mathrm{min}$ at $40-\mathrm{min}$ after infusion $(P$ $<0.05$, Fig. 1 c). No significant changes in $\mathrm{Cl}$ excretion were observed in the control rats.

In time control rats infused with vehicle, mean arterial pressure (MAP) decreased from $103 \pm 2.2$ to $96 \pm 3.5 \mathrm{~mm} \mathrm{Hg}(P$ $<0.05$, Fig. $1 d$ ). In contrast, MAP did not significantly change with time in the AmB-treated rats. MAP at 40 min after terminating $A m B$ infusion reached $109 \pm 3.2 \mathrm{~mm} \mathrm{Hg}$.

Single-nephron studies. The results of this experimental series are summarized in Table I. In the control period, mean SNGFR measured in distal tubular segments of $30.6 \pm 1.2 \mathrm{nl} /$ min was significantly lower than SNGFR in paired proximal segments of $33.4 \pm 1.8 \mathrm{nl} / \mathrm{min}(P<0.05)$. Mean values for proximal and distal SNGFR in the second half of the AmB infusion period were $19.7 \pm 1.9$ and $21.2 \pm 1.6 \mathrm{nl} / \mathrm{min}$, respectively. Mean SNGFR values during the first hour after terminating AmB infusion recovered and were not significantly different from control values. However, in the period 60-120 min after AmB infusion proximal SNGFR averaged $19.7 \pm 1.6 \mathrm{nl} / \mathrm{min}$ and mean distal SNGFR was $18.7 \pm 0.4 \mathrm{nl} / \mathrm{min}$. $C_{\ln }$ was $0.44 \pm 0.01$ $\mathrm{ml} / 100 \mathrm{~g} \mathrm{BW}$ per min in the control period, $0.34 \pm 0.03$ during $A \mathrm{mB}$ infusion, $0.39 \pm 0.03$ in the first hour, and $0.35 \pm 0.03 \mathrm{ml} /$ $100 \mathrm{~g} \mathrm{BW}$ min in the second hour after AmB infusion $(P<0.05$ for all comparisons with control).

Distal $\mathrm{Cl}$ concentrations tended to increase during and in the first hour after AmB infusion from a control value of $49.1 \pm 13.4$ to $66.5 \pm 10.1$ and $61.5 \pm 4.1 \mathrm{mM}$ without reaching the $5 \%$ significance level. Distal $\mathrm{Cl}$ concentration was $49.9 \pm 4.9$ $\mathrm{mM}$ in the $60-120-\mathrm{min}$ postinfusion period at the time where both whole kidney and single nephron filtration rate were significantly depressed (Table I). Mean arterial pressure averaged $107 \pm 4.1,108 \pm 4.1,104 \pm 3.2$, and $105 \pm 3.7 \mathrm{~mm} \mathrm{Hg}$ before, during, and in the first and second hour after AmB, respectively.

$T G F$ sensitivity. Stop flow pressure $\left(P_{\mathrm{SF}}\right)$ at zero flow was not different between control tubules and tubules studied during and immediately after AmB infusion (Fig. 2). However, $P_{\mathrm{SF}}$ at zero flow decreased significantly in the second hour after termination of AmB infusion presumably indicating a fall in glomerular capillary pressure despite the interruption of distal flow. $P_{\mathrm{SF}}$ responses to changes in loop flow were comparable in all periods as indicated by similar maximum reductions of $P_{\mathrm{SF}}$ and similar values for the feedback curve parameters $V_{1 / 2}$ and $\mathrm{k}$ (Table II). Arterial pressure was $121 \pm 3.2,119 \pm 2.8,118 \pm 5$, and $115 \pm 5.2 \mathrm{~mm} \mathrm{Hg}$ before, during, and in the first and second hour after AmB, respectively.

Effect of $A m B$ on $P_{S F}$. The possibility of a direct and acute vasoconstrictor action of $\mathrm{AmB}$ was tested in vivo by assessing the effect of peritubular AmB infusion on $P_{\mathrm{SF}}$ at zero loop perfusion. Infusion of a Ringer solution containing $10^{-4} \mathrm{M}$ AmB into peritubular capillaries decreased $P_{\mathrm{SF}}$ acutely from $46.2 \pm 0.9$ to $40.6 \pm 1.2 \mathrm{~mm} \mathrm{Hg}$. This decrease in $P_{\mathrm{SF}}$ was transient, returning to a steady mean value of $44.3 \pm 1.3 \mathrm{~mm} \mathrm{Hg}$ within $1 \mathrm{~min}$. An original recording of such an experiment is shown in Fig. 3. Peritubular infusion of Ringer solution containing $10^{-4} \mathrm{M}$ Na deoxycholate had no effect on $P_{\mathrm{SF}}(n=4)$.

Serum AmB level. Mean serum AmB concentration at the end of $A m B$ infusion was $5.0 \pm 0.6 \mu \mathrm{M} .30$ and 90 min later serum AmB levels averaged $3.6 \pm 0.2$ and $3.9 \pm 0.3 \mu \mathrm{M}$, respectively.

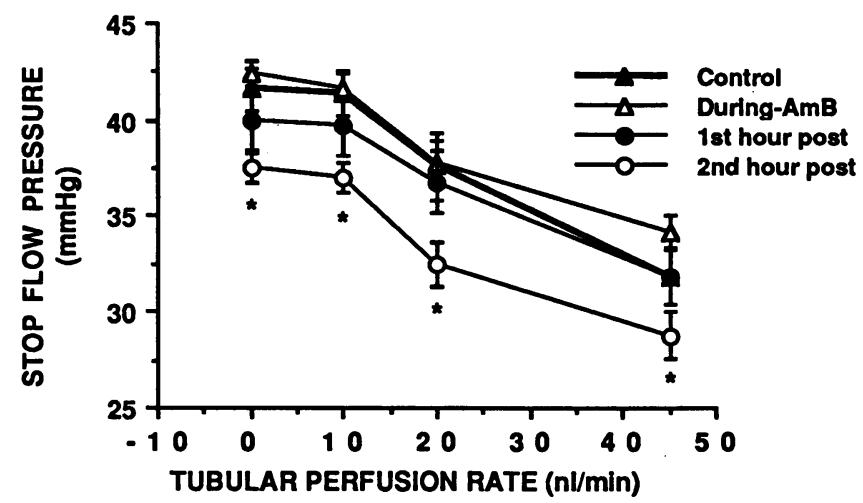

Figure 2. Tubuloglomerular feedback response of stop flow pressure to changes in loop of Henle perfusion rate in control $(\triangle)$, during AmB infusion $(\Delta)$, and in the first and second hour after AmB infusion (• and 0 , respectively). ${ }^{*} P<0.05$ vs. control. 
Table II. Tubuloglomerular Feedback Parameters before, during, and after AmB Infusion

\begin{tabular}{lcccc}
\hline & Control & During & After 1st h & After 2nd h \\
\hline$\Delta P_{\text {SF-max }}(m m H g)$ & $9.7 \pm 0.8$ & $8.2 \pm 0.7$ & $8.1 \pm 0.8$ & $8.7 \pm 0.9$ \\
$\Delta P_{\text {SF-max }}(\%)$ & $23.8 \pm 2.1$ & $19.4 \pm 1.7$ & $20.3 \pm 2.1$ & $23.2 \pm 2.4$ \\
$\dot{V}_{1 / 2}($ nl/min $)$ & $21.2 \pm 0.88$ & $19.2 \pm 1.06$ & $25.0 \pm 3.3$ & $19.1 \pm 1.19$ \\
$K(\text { (nl/min })^{-1}$ & $0.32 \pm 0.12$ & $0.26 \pm 0.08$ & $0.14 \pm 0.05$ & $0.32 \pm 0.16$ \\
$n($ rats $/$ tubules $)$ & $4 / 14$ & $4 / 10$ & $4 / 15$ & $4 / 9$
\end{tabular}

Parameters: $P_{\mathrm{SF}}=$ stop flow pressure; $\Delta P_{\mathrm{SF}-\max }=$ maximum decrease in stop flow pressure, $\dot{V}_{1 / 2}=$ perfusion rate at which the decrease in $P_{\mathrm{SF}}$ is half maximum, $K=$ exponential constant defined as: $\left[4 \times f^{\prime}\left(\dot{V}_{1 / 2}\right)\right] / \Delta P_{\text {SF-max }}$, with $f^{\prime}\left(\dot{V}_{1 / 2}\right)$ referring to the slope of the curve at the midpoint.

\section{Effect of AmB on isolated vessels of rabbits}

Afferent arterioles. AmB at $10^{-5} \mathrm{M}$ significantly reduced the diameter of perfused afferent arterioles $(n=7)$. The reduction in vessel diameter waned somewhat at exposure times longer than $3 \mathrm{~min}$, but vessels remained constricted compared to control. The vessel response to AmB was usually inhomogeneous as can be seen in the example shown in Fig. 4. The most consistently responsive part of the arteriole was the segment at the entrance into the glomerulus. Other responsive foci were located at irregular distances from the glomerulus. Fig. 5 shows individual and mean vessel diameter changes caused by AmB in a more (top) and in a less responsive segment (bottom). Mean diameter of the responsive segments in control was 12.6 11.2 $\mu \mathrm{m}(n=7)$, decreasing to $6.3 \pm 1.5 \mu \mathrm{m}$ at $3 \mathrm{~min}(P<0.01)$ and to $8.6 \pm 1.4 \mu \mathrm{m}$ at $10 \mathrm{~min}$ of $\mathrm{AmB}$ exposure $(P<0.01)$. After removal of $A m B$ vessel diameters returned to control within 10-20 min. A significant reduction in vessel diameter was also seen in the nonsphincter segment in which mean diameter decreased from $17.4 \pm 1.44$ to $14.5 \pm 1.15(P<0.05)$ and $14.6 \pm 1.4$ $\mu \mathrm{m}(P<0.05)$ at 3 and $10 \mathrm{~min}$ of AmB exposure. Nifedipine $\left(10^{-5} \mathrm{M}\right)$ fully inhibited the contractile response of $\mathrm{AmB}$ in both sphincterlike segments (diameter in micrometers: $10.7 \pm 1.5$ in control, $12.3 \pm 2.1$ at $3 \mathrm{~min}$, and $11.2 \pm 1.07$ at 10 $\min ; n=4$ ) and nonsphincter segments (diameter in micrometers: $15.6 \pm 1.66$ in control, $15.7 \pm 1.6$ at $3 \mathrm{~min}$, and $15.8 \pm 1.6$ at $10 \mathrm{~min} ; n=4)$.

Aorta and renal artery. 38 experiments on rings of rabbit aorta were performed to assess contractile responses to increasing concentrations of AmB. Since preliminary studies indi-

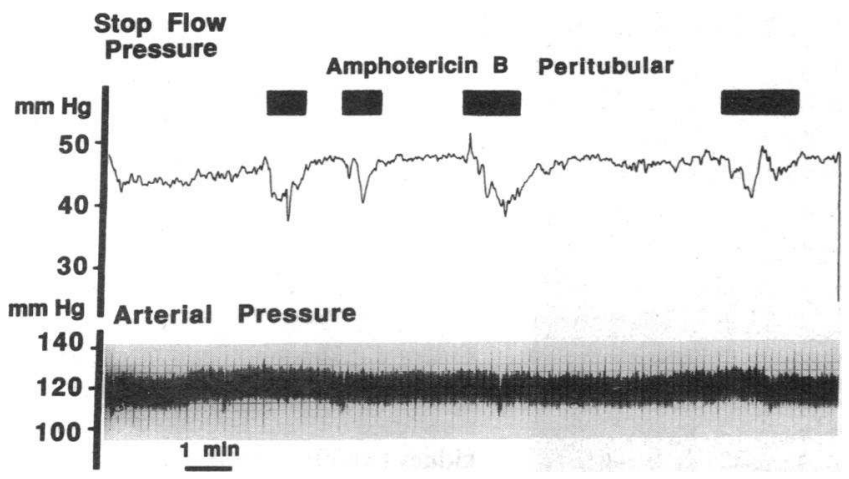

Figure 3. Original recording showing the effect of peritubular application of AmB on stop flow pressure (upper tracing). Periods of peritubular AmB infusion are indicated by block bars. Lower tracing shows arterial blood pressure. cated that prior exposure of vessels to AmB might augment the response to subsequent $\mathrm{AmB}$ administration each concentration was tested in four to eight rings exposed to a single drug concentration only. In Fig. 6 data are expressed as percentage of the vasoconstrictor effect of $100 \mathrm{mM} \mathrm{KCl}$ which in terms of force development was $2,524 \pm 102 \mathrm{mg}$ in the intact vessels and $1,637 \pm 114 \mathrm{mg}$ in the vessels which had their endothelium removed. AmB produced isometric contractions in a concentration-dependent fashion with most of the effect occurring between $10^{-6}$ and $10^{-5} \mathrm{M}$ (Fig. $6 \mathrm{a}$ ). Maximum force generation was comparable to that produced by $100 \mathrm{mM} \mathrm{KCl}$. The contractile effect of AmB was not significantly different between intact and endothelium-denuded vessels although tension development tended to be consistently larger in the absence of the endothelium. The AmB concentration producing half maximal contraction $\left(\mathrm{EC}_{50}\right)$ was $1.8 \times 10^{-6} \mathrm{M}$ in intact vessels and $1.3 \times 10^{-6} \mathrm{M}$ in the denuded vessels. A vasoconstrictor effect of AmB was also seen in isolated rings of the renal artery (Fig. $6 b$ ). Force generation in response to $100 \mathrm{mM} \mathrm{KCl}$ in these vessels was $1,852 \pm 153 \mathrm{mg}$ in intact vessels and $1,745 \pm 146 \mathrm{mg}$ in denuded vessels. $\mathrm{EC}_{50}$ of AmB-induced contraction was 2.6 $\times 10^{-6}$ in intact vessels and $1.7 \times 10^{-6}$ in denuded rings. Vessels exposed to the vehicle deoxycholate did not generate any force even at a relatively high dose of $5 \times 10^{-4}$.

The time course of the contractile response to AmB was slow with $t_{1 / 2}$, the time to reach half-maximal contraction to 6 $\times 10^{-6} \mathrm{M} \mathrm{AmB}$, being $19.3 \pm 3.2 \mathrm{~min}$ in intact and $18.6 \pm 2.2$ min in denuded vessels (Fig. 7 a). Likewise, a time span of 45 min elapsed to achieve half-maximal relaxation after removal of the drug. In renal arteries the time course of changes in tension following addition or removal of AmB was similarly sluggish and comparable to that found in the aorta (Fig. $7 \mathrm{~b}$ ).

Role of calcium and calcium channels in AmB-induced contractions. Addition of $\mathrm{AmB}(10 \mu \mathrm{M})$ to aortic rings suspended in calcium-free solutions $\left(0 \mathrm{CaCl}_{2}+1 \mathrm{mM}\right.$ EGTA) was essentially without effect on tension (Fig. 8). When $1.6 \mathrm{mM} \mathrm{CaCl}_{2}$ was added in the presence of AmB there was a force generation with a time course much faster than seen in nonpreincubated vessels. Pretreatment with verapamil (1 $\mu \mathrm{M}$ for $30 \mathrm{~min})$ significantly blunted the vasoconstrictor effect of $10 \mu \mathrm{M} \mathrm{AmB}$ in both intact and endothelium-denuded vessels (Fig. $9 a$ ). Verapamil added to aortic rings during AmB-induced contraction $(10 \mu \mathrm{M})$ caused a reduction in the force generated with an $\mathrm{EC}_{50}$ of 2 $\times 10^{-7} \mathrm{M}$ (Fig. $9 \mathrm{~b}$ ). Similar results were obtained in denuded vessels.

Effect of ouabain and BAYK 8644 on AmB-induced contractions. In aortic rings, pretreatment with ouabain $(1 \mu \mathrm{M}$ for 30 $\mathrm{min}$ ) potentiated as well as accelerated the tension generated by 

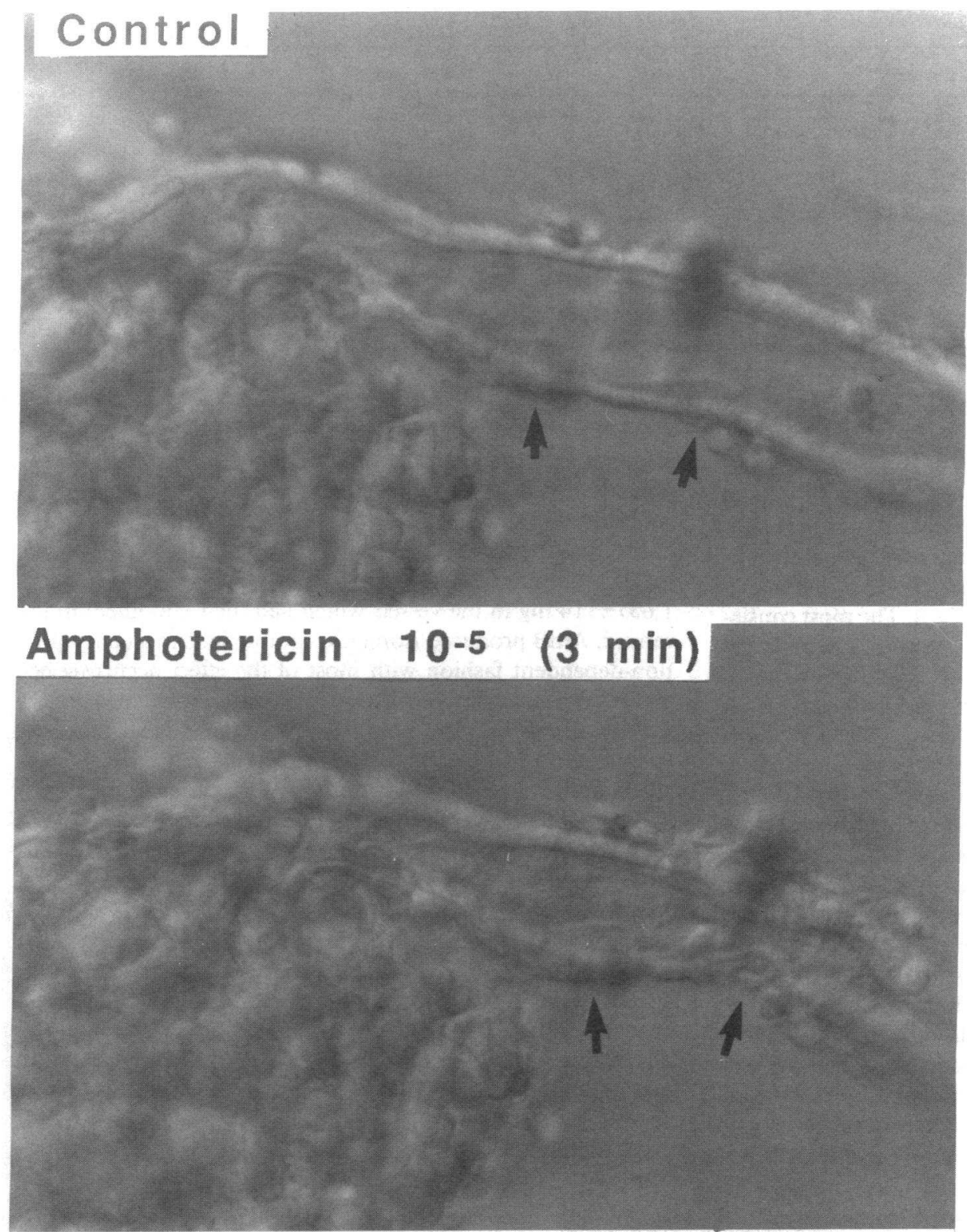

\section{Amphotericin $10-5 \quad(10 \mathrm{~min})$}

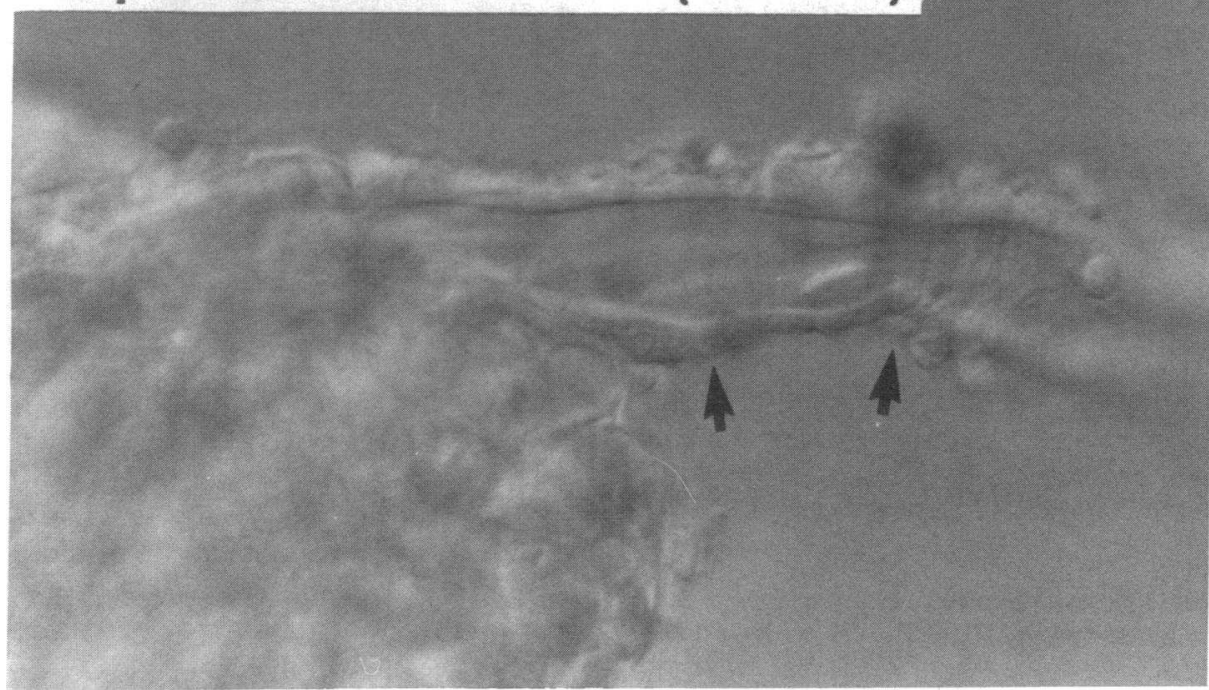

Figure 4. Microphotographs showing the effect of AmB on the diameter of a perfused afferent arteriole from rabbit kidney $(\times 600)$. Arrows indicate sites at which diameter measurements were made. Note contractility differences in the more responsive (right arrows) and less responsive segments (left arrows). 

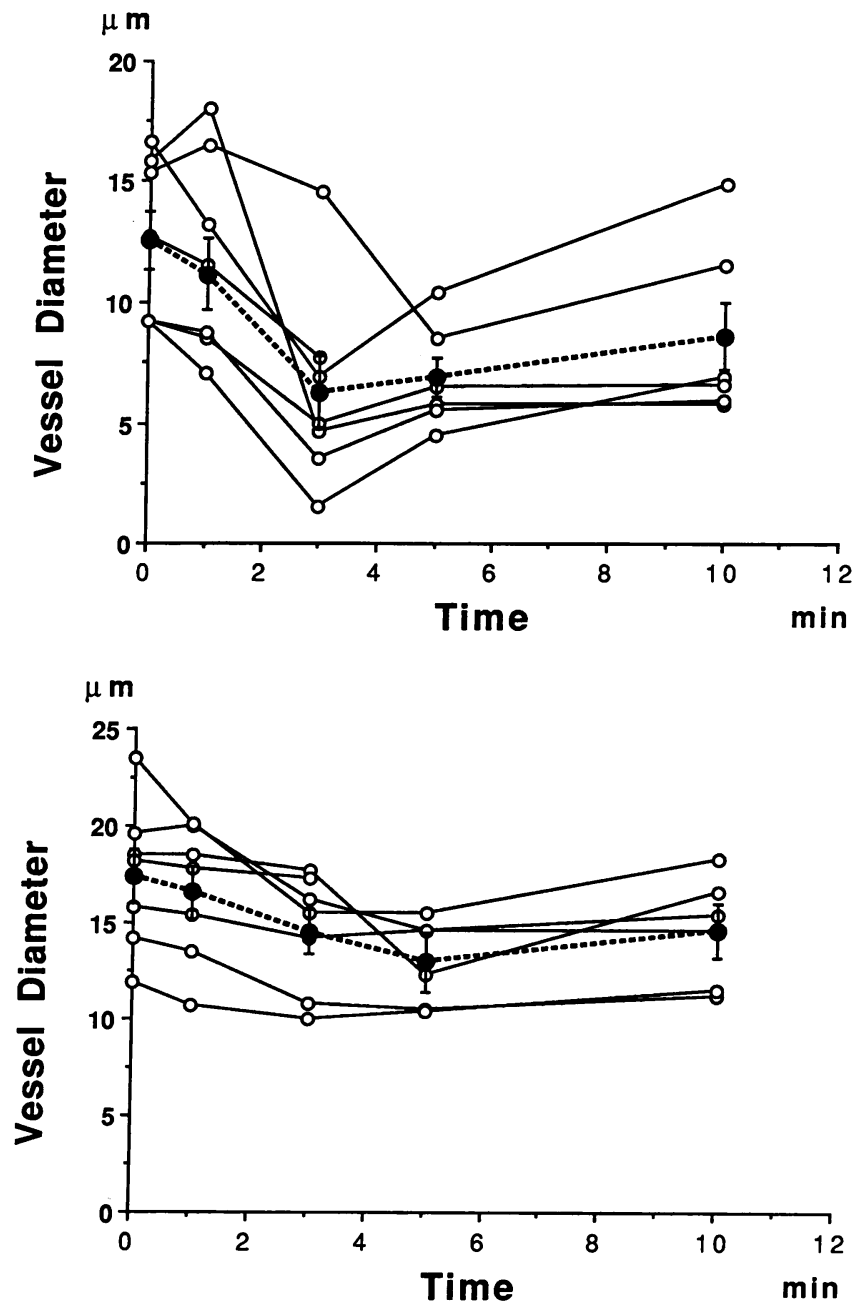

Figure 5. AmB-induced changes in the diameter of afferent arterioles in more (top) and less responsive segments of the vessel (bottom). Open symbols and solid lines indicate individual vessel responses; closed symbols and broken lines indicate diameter changes.

$10 \mu \mathrm{M}$ AmB (Fig. 10; $n=6$ ). In some vessels in which ouabain caused some contraction AmB-induced tension was measured from that level of tension. $T_{1 / 2}$, the time to reach half-maximum force generation, was $9.7 \pm 3.4$ min compared to $21.9 \pm 4.2$ in control vessels $(P<0.05)$. As shown in Fig. 11 exposure of aortic rings to BAY K 8644 produced little constrictor effects. However, pretreatment with a substreshold concentration of AmB significantly potentiated the effect of BAY K 8644 .
Effect of theophylline and ANP on AmB-induced contractions. As shown in Fig. 12, theophylline and ANP reduced the force generated by $10^{-5} \mathrm{MAmB}$. $\mathrm{EC}_{50}$, the concentration to produce half-maximal responses, was $2.8 \times 10^{-8} \mathrm{M}$ with ANP and $1.5 \times 10^{-4} \mathrm{M}$ with aminophylline. Similar results were observed in the denuded vessels.

Effect of phentolamine. Alpha adrenergic blockade was associated with a significant, albeit modest reduction in the force generated by AmB in both intact and denuded vessels. Expressed as percent of contraction caused by $100 \mathrm{mM} \mathrm{KCl}, 1 \mu \mathrm{M}$ phentolamine reduced the tension developed by $10 \mu \mathrm{M} \mathrm{AmB}$ from $73.6 \pm 10.3 \%$ to $58.7 \pm 8.4 \%$ in intact vessels $(n=4 ; P$ $<0.05$ ) and from $115 \pm 9.8 \%$ to $98.8 \pm 7.2 \%$ in denuded vessels $(n=4, P<0.05)$.

\section{Discussion}

$\mathrm{AmB}$ has proven to be a useful therapeutic agent for the treatment of systemic fungal infections. Its beneficial actions however are limited by the relatively frequent occurrence of nephrotoxic side effects, particularly reductions in GFR (6-8). Using animal models of AmB nephrotoxicity, attempts have been made to clarify the mechanisms responsible for AmB-induced changes in renal function. Results from such studies led to the suggestion that the hemodynamic alterations caused by $\mathrm{AmB}$ are secondary to a change in tubular $\mathrm{NaCl}$ absorption with subsequent activation of the tubuloglomerular feedback (TGF) mechanism $(8,11,18,19,24)$. Since this proposal is based on observations in the whole kidney, and had not been directly tested at the single nephron level, we performed micropuncture studies to examine whether TGF has a causal role in AmB-induced changes of renal hemodynamics.

Consistent with the results of earlier studies the present experiments show that $A m B$ infusion in rats induced both an acute and a persistent reduction in $\operatorname{GFR}(8,9)$. The fact that the decrease of GFR was less pronounced than in an earlier study by Cheng et al. (9) may be related to the fact that our animals were maintained in a euvolemic state by the infusion of albumin-containing saline. Extracellular fluid volume has been shown to modulate the effect of $\operatorname{AmB}(11,25)$. A greater fall of GFR was in fact seen in the hydropenic animals used for micropuncture. In these rats GFR fell by $23 \%$ during the infusion of $A m B$, a decrease similar to that observed in another recent micropuncture study (24). In the absence of consistent inulin leakage, the clearance of inulin can be taken as a measure of glomerular filtration rate. In contrast to the present results, Cheng et al. (9) have reported that AmB induced a marked and progressive reduction of inulin recovery. The reason for the

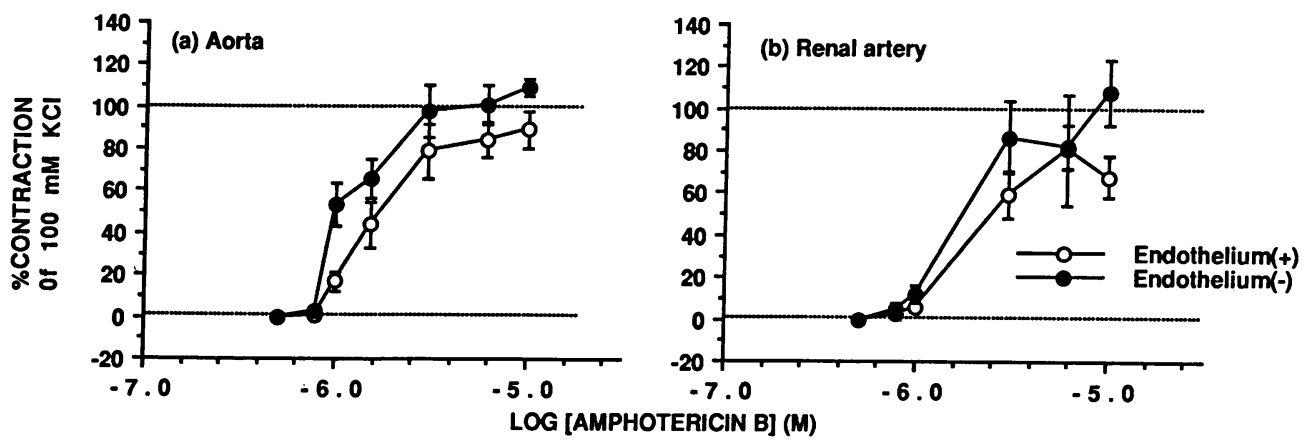

Figure 6. Effect of AmB on isometric contractions of $(a)$ isolated rabbit aorta and $(b)$ renal artery. Contractions are expressed in percent of the constrictor effect of $100 \mathrm{mM} \mathrm{KCl}$. (०) Intact vessels; (๑) endothelium-denuded vessels. 

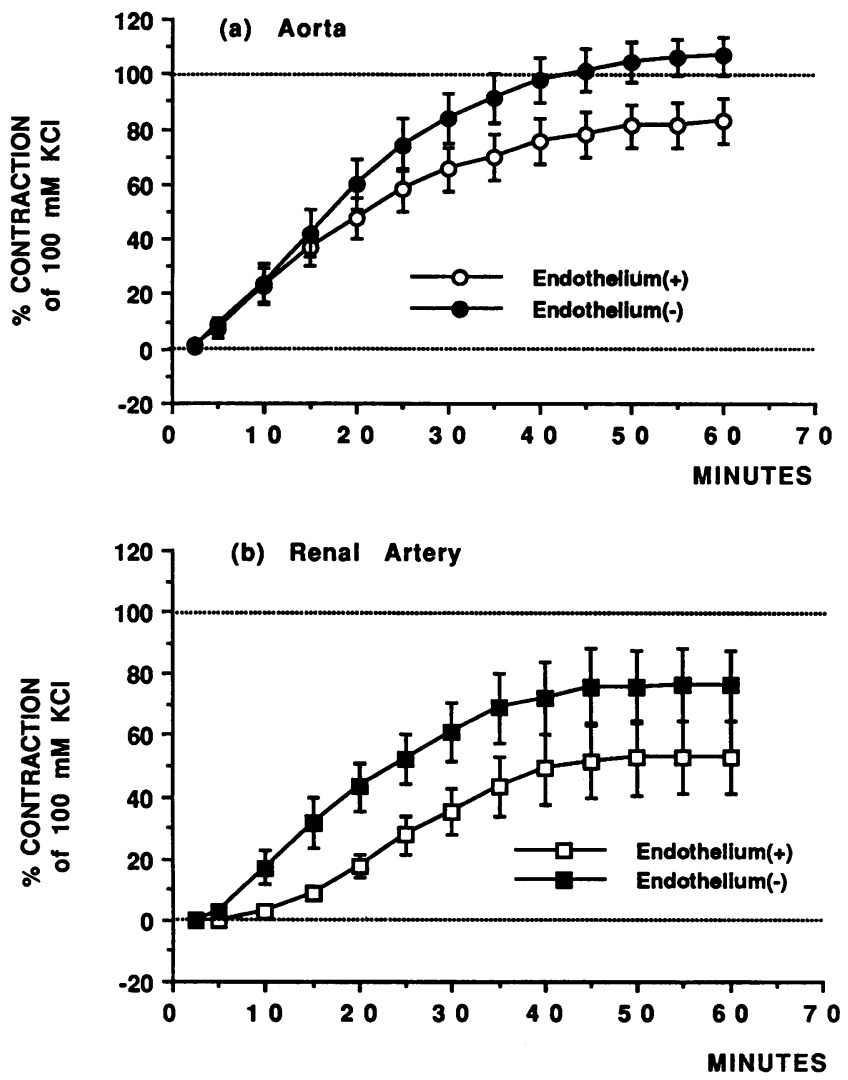

Figure 7. Time course of tension development in response to $6 \mu \mathrm{M}$ of AmB in rings from $(a)$ rabbit aorta and $(b)$ renal artery in the presence or absence of a functional endothelium.

discrepancy between these results may lie in differences in the experimental protocol. Cheng et al. (9) performed their studies in mannitol diuresis and it is possible that the combination of

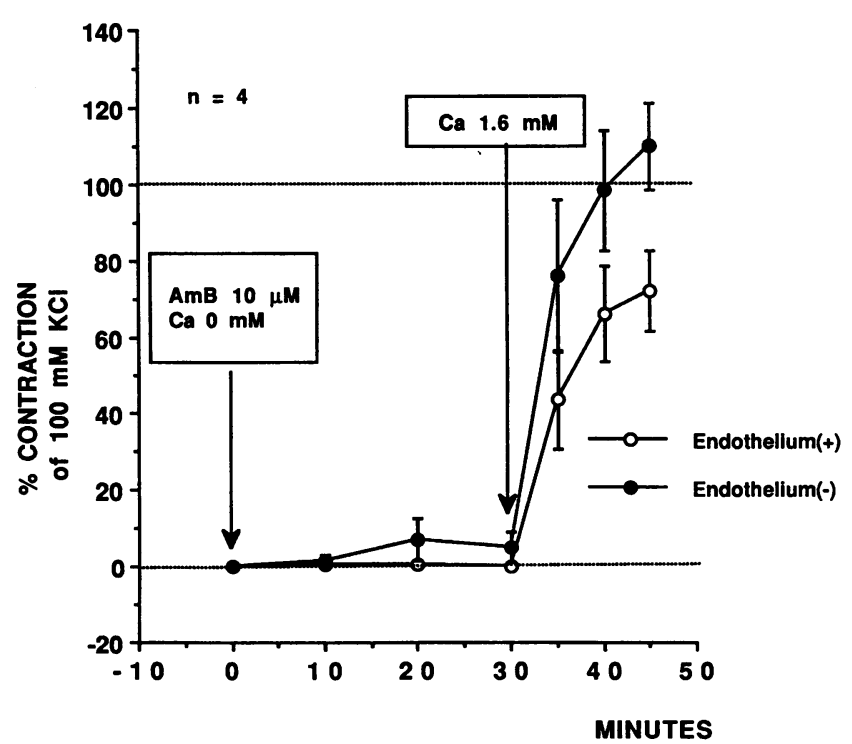

Figure 8. Effect of extracellular calcium concentration on AmB-induced vasoconstriction. Arrows indicate the time of AmB or calcium addition to the bath. ( $(0)$ Intact vessels; (๑) endothelium-denuded vessels.
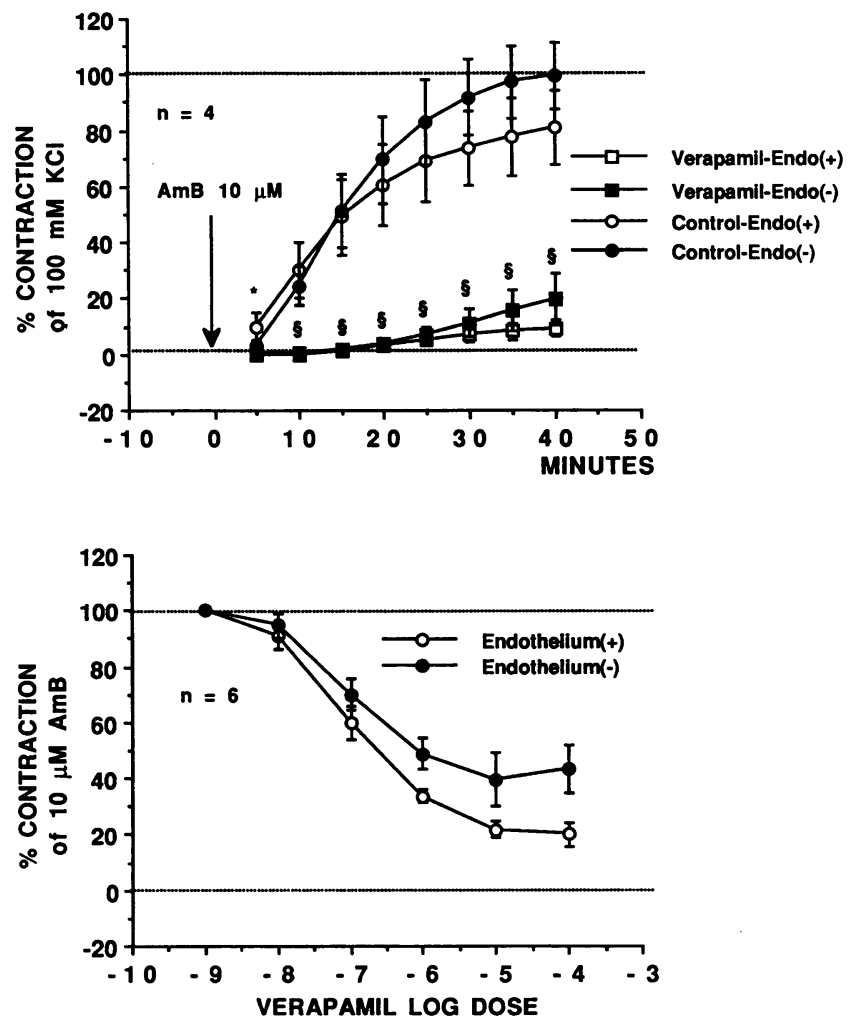

Figure 9. (top) Effect of 30-min pretreatment with verapamil (1 $\mu \mathrm{M})$ on vasoconstriction induced by $10 \mu \mathrm{M}$ AmB. Circles: control vessels; squares: verapamil-treated vessels. Open symbols: intact rings; closed symbols: endothelium-denuded rings. ${ }^{*} P<0.05 ;{ }^{8} P<0.001$. (Bottom) Effect of verapamil on the tension generated by the presence of 10 $\mu \mathrm{M} \mathrm{AmB}$ in intact (o) and endothelium-denuded rings of rabbit aorta $(\bullet)$.

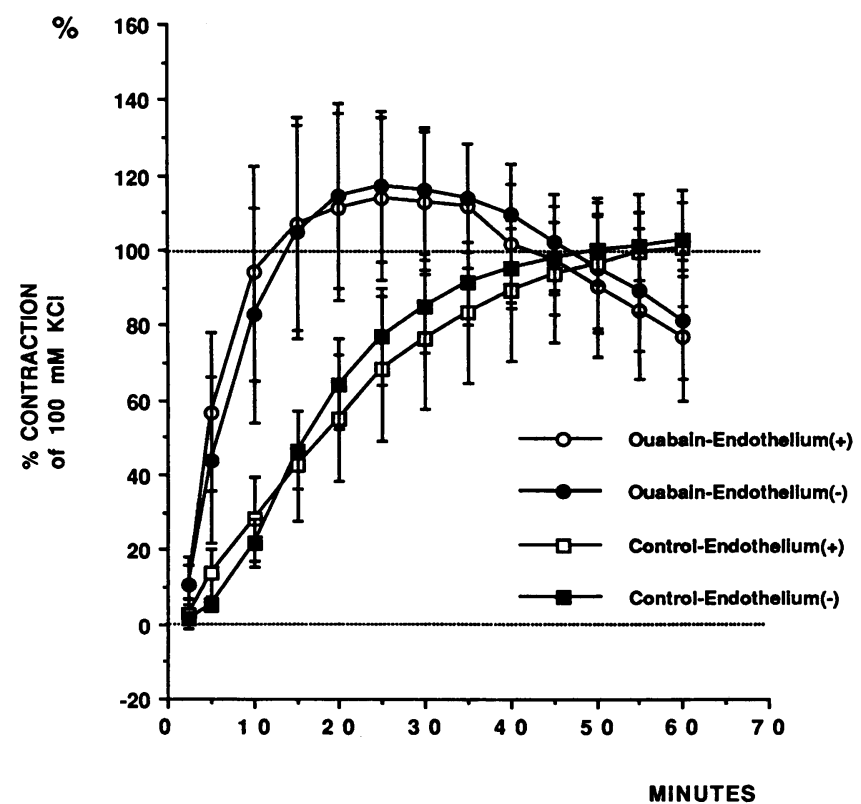

Figure 10. Effect of 30-min pretreatment with ouabain $(1 \mu \mathrm{M})$ on vasoconstriction induced by $10 \mu \mathrm{M}$ AmB. Squares: control vessels; circles: ouabain-treated vessels. 


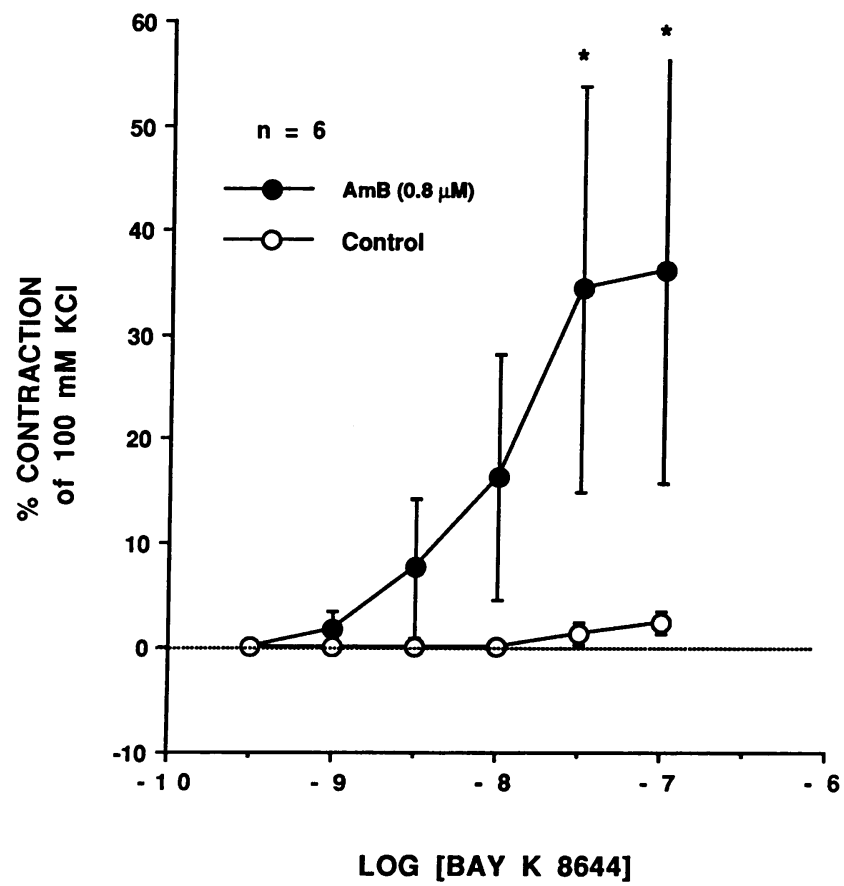

Figure 11. Relationship between BAY K 8644 concentration and contractile responses of rabbit aortic rings to subthreshold concentrations of AmB. (०) Control vessels; (๑) vessels pretreated with AmB $(0.8 \mu \mathrm{M}) .{ }^{*} P<0.05$.

mannitol and AmB augmented the permeabilizing effect of AmB. Some evidence suggests that AmB in combination with mannitol in man alters morphology to a greater extent than AmB alone (26). Erroneous overestimates of inulin leakage can be caused by a number of technical problems, such as absorption of low molecular weight breakdown products of labeled inulin, or unrecognized loss of injectate.

To examine a possible participation of the TGF system in the AmB-induced reduction of GFR we first determined the effect of AmB on SNGFR in the absence and presence of a macula densa signal. If AmB suppresses GFR by an increased $\mathrm{NaCl}$ delivery to the macula densa and subsequent TGF activation, blockade of the TGF signalling pathway should prevent the AmB-induced fall of GFR. Our results show that blockade

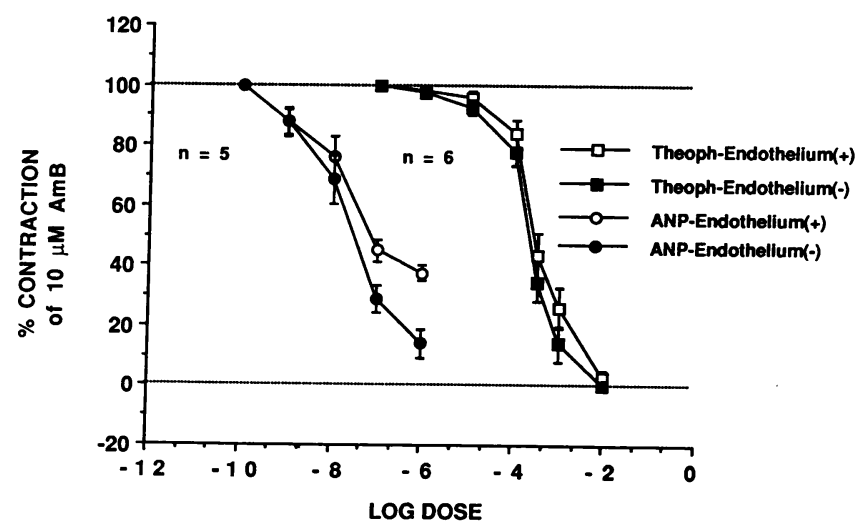

Figure 12. Effect of aminophylline (squares, $n=6$ ), and atrial natriuretic peptide, ANP (circles, $n=5$ ) on the vasoconstrictor effect of $\mathrm{AmB}(10 \mu \mathrm{M})$ in isolated rings of rabbit aorta. of the macula densa signal by proximal fluid collections did not increase filtration rate during AmB administration. Low SNGFR in the absence of distal $\mathrm{NaCl}$ delivery has also been noted in another recent micropuncture study (24). Thus, distal fluid delivery does not appear to be critical for the maintenance of AmB-induced vasoconstriction. The absence of a demonstrable effect of blocking the TGF pathway on the AmB-induced fall in GFR is consistent with the finding that distal $\mathrm{Cl}$ concentration, the presumed signal in TGF-mediated vasoconstriction, did not increase significantly. These observations seem incompatible with the notion of $\mathrm{NaCl}$-dependent $\mathrm{TGF}$ activation being primarily responsible for AmB-induced reductions in GFR. We also addressed the possibility that TGF-mediated AmB nephrotoxicity could result from an increase in TGF sensitivity. These studies showed that the characteristics of the feedback response to changes in loop perfusion rate, both $V_{1 / 2}$ and maximum responses, were not detectably altered by AmB. Thus, no measurable resetting of TGF sensitivity occurred that could have affected arteriolar tone in a way not predictable from the changes in distal $\mathrm{Cl}$ concentrations.

Since our studies did not provide evidence for a major role of TGF in AmB-induced reductions of GFR, we examined the possibility that $\mathrm{AmB}$ administration may cause constriction of blood vessels by a direct effect on smooth muscle cells, an alternative that, to our knowledge, has not been studied previously. Since it is difficult to differentiate between direct and indirect vasomotor responses in the intact organism, we examined the vasoactive properties of $A m B$ in vitro in both large and small vessels. Our studies show that $A m B$ is a potent vasoconstrictor of preglomerular arterioles and both renal and nonrenal arteries. Previous indirect evidence is in agreement with the conclusion that vasoconstriction is not limited to the preglomerular vascular bed, as one would expect if the TGF mechanism or another strictly intrarenal mechanism were primarily responsible for the nephrotoxic actions of AmB. Experimental animals frequently show an increase of mean arterial pressure suggestive of an increase in systemic vascular resistance $(7,11,19$, 27). For example, Reiner et al. (27) have shown in studies in dogs that intravenous AmB administration increased not only renal vascular resistance, but also pulmonary and total systemic resistance. The fall in cardiac output reported in that study may explain the absence of more severe hypertension after AmB infusion (27).

Our studies indicate that AmB-induced vasoconstriction can be elicited in a setting where an influence of central and reflex-mediated effects can be excluded. It is conceivable, however, that the vasoactive effect of AmB may be dependent upon, or modified by, the local release of vasoactive autacoids. A slight, but consistent increase in the constrictor response to AmB was seen after mechanical removal of a functional endothelium, suggesting that the effect of AmB may be blunted by the release of endothelium-derived relaxing factor. Furthermore, AmB effects were slightly reduced by phentolamine, indicating a possible contribution of norepinephrine released from nerve endings within the vessel wall to AmB-induced vasoconstriction. Further studies are required to explore the effect of AmB on generation and release of locally active agents.

The results of the present experiments indicate that AmBproduced changes in renal function and in vascular tone follow a complex time course. Exposure to AmB produced an immediate effect, as seen in the constrictor response of isolated arterioles, in the stop flow pressure response during peritubular infu- 
sion of AmB, and in the rapid onset of demonstrable reductions in SNGFR. This immediate reaction to AmB appears to decrease in magnitude despite continued presence of the drug. The response in large vessels, on the other hand, was slower in onset, requiring $\sim$ 40-50 min for peak effects, and persistent for a longer time after withdrawal of the drug. This long-lasting action of AmB may be of particular importance for the development of nephrotoxic side effects. It is to be pointed out that although the rate of relaxation in vitro was faster (half-maximum relaxation of $45 \mathrm{~min}$ ) than the recovery of GFR in vivo, these results are not necessarily in contradiction. When AmB is withdrawn from the bath in vitro, the decay is likely to reflect removal of $\mathrm{AmB}$ from the membrane pool. In the in vivo experiments, on the other hand, AmB levels in plasma are known to remain elevated for prolonged periods of time after termination of AmB infusion (28). The difference in the temporal pattern of AmB-induced vasoconstriction may indicate a different constrictor mechanism in small or large vessels. Since it is likely that incorporation of AmB into the membranes of smooth muscle cells is a prerequisite for its biological actions, it is also possible that the time course of entry and removal of the drug from the membrane may be different in vessels of varying calibers.

Our results furnish some insight into the causes for the delayed vasomotor effects of the drug. The abolition of constrictor effects in Ca-free solutions together with the inhibitory effect of the $\mathrm{Ca}$ channel blocker verapamil strongly indicates a dependence of AmB-induced vasoconstriction on $\mathrm{Ca}$ influx through voltage-dependent $\mathrm{Ca}$ channels. Earlier findings of Tolins et al. (8) had already shown that verapamil completely abolished the acute effect of AmB on renal blood flow. Recent evidence indicates that $\mathrm{AmB}$ can act as a calcium ionophore in sterol-containing liposomes (29). However, the concentration of $\mathrm{AmB}$ required to induce $\mathrm{Ca}$ entry into liposomes was substantially higher than AmB concentrations needed to induce vasoconstriction. Furthermore, one may not expect verapamil to block an ionophore effect of AmB, so that entry of $\mathrm{Ca}$ through pores formed by AmB may be unlikely. On the other hand, AmB incorporated into membranes generates channels that are preferentially permeable to univalent ions $(13,14,30)$. Exposure to AmB is thus predicted to cause cell depolarization owing to increased sodium influx, an effect which has been demonstrated in skeletal muscle cells (31) and necturus gallbladder cells (32). Depolarization may be followed by increased calcium influx through voltage-gated $\mathrm{Ca}$ channels (33). Indirect evidence for a depolarizing effect of AmB in our studies is furnished by the observation that low concentrations of ouabain significantly accelerated the onset of AmB actions. We assume that the depolarizing effect of ouabain was additive to that of AmB in facilitating the entry of $\mathrm{Ca}$ (34). Furthermore, BAY K 8644 did not cause vasoconstriction in untreated rings of rabbit aorta as shown earlier (35), but produced constriction in the presence of subthreshold concentrations of AmB. It has been shown that facilitation of $\mathrm{Ca}$ entry by dihydropyridine agonists is voltage-dependent and can be elicited by slight cell depolarization (35-37), an effect that may have been produced by exposure to AmB. The validity of this likely mechanism of AmB action needs to be studied with direct methods.

The hypothesis of a causal role of the TGF system in AmB nephrotoxicity was based for the most part on the blunting of AmB-induced vasoconstriction that accompanies interventions known to block TGF-mediated vascular effects such as salt loading or the administration of furosemide, aminophylline or verapamil $(8,11,18,19)$. The present studies provide possible alternative explanations for some of these observations. Acute salt loading is associated with a reduction in sympathetic tone and plasma renin concentration as well as an increase in plasma levels of atrial natriuretic peptide. The resulting relative relaxation of the renal vasculature caused by volume expansion may reduce the vasoconstrictor potential of $\mathrm{AmB}$, a possibility supported by previous studies showing that the combination of saralasin and low dose dopamine attenuated the renal constrictor effect of AmB (27) and by the present observation that the contractile response of isolated vessels to $\mathrm{AmB}$ was reduced by atrial natriuretic peptide. We believe that the attenuation of the acute effects of AmB on GFR in volume replaced compared to hydropenic rats may also reflect the modulatory influence of other vasoactive agents on the direct vascular actions of AmB. At the cellular level this modulation of AmB effects may be caused by relative cell hyperpolarization, a decrease in cytosolic $\mathrm{Ca}$, and an increase in cellular cAMP and CGMP levels. Aminophylline has been shown both to reduce the nephrotoxic effect of $\operatorname{AmB}(18,19)$ and to inhibit the TGF mechanism (17). Since in the present study aminophylline antagonized the constrictor action of AmB in isolated vessels, it appears that aminophylline may alter the vascular response to AmB by a direct effect rather than by inhibiting the TGF mechanism. The high concentrations of aminophylline required to blunt the vasomotor action of $\mathrm{AmB}$ suggest that aminophylline may interfere with contractile responses by increasing cyclic nucleotide levels following inhibition of phosphodiesterase. As suggested above, the protective effect of verapamil may result from the central role of voltage-activated Ca channels in AmB-induced vasoconstriction. Finally, there is experimental evidence to suggest that furosemide has direct effects on smooth muscle cells which may be related to its beneficial actions in AmB nephrotoxicity (11). Furosemide has been shown to counteract the effect of phenylephrine-induced contractile responses in rat aorta (38) and to decrease systemic vascular resistance in functionally anephric humans (39). We have not tested the influence of furosemide on the vasoconstrictive effect of AmB in isolated vessels of the rabbit because previous results suggest insensitivity of rabbit smooth muscle cells to furosemide (38). Although further work is needed to fully understand the protective effects of salt loading, aminophylline and in particular furosemide, our results provide solid experimental support for an alternative explanation of the renal hemodynamic actions of AmB that is independent of TGF activation. Another argument supporting the concept of TGF-mediation of AmB vasoconstriction has been the observation that the changes in the determinants of glomerular ultrafiltration caused by AmB administration were similar to those induced by the macula densa signal $(12,24)$. However, our studies show that AmB can induce vasoconstriction of afferent arterioles in vitro and a fall in SNGFR in vivo, both in the absence of a functional TGF system. Thus, the identity of the vascular effects of AmB and TGF cannot necessarily be taken as indicative of a causal link.

In conclusion, the results of the present studies do not support the proposal that the effect of AmB on GFR is caused by TGF activation subsequent to an elevation in distal $\mathrm{NaCl}$ delivery. In isolated perfused afferent arterioles and in rings of aorta and renal artery, AmB causes dose-dependent and endothelium-independent vasoconstriction probably by augmenting 
$\mathrm{Ca}$ influx through voltage-gated $\mathrm{Ca}$ channels. Aminophylline and atrial natriuretic peptide attenuated the constrictor effect of AmB suggesting a role for cyclic nucleotides as intracellular antagonists of AmB activation. These observations are consistent with the hypothesis that a direct AmB-induced vasoconstriction may be an important factor in the reduction of GFR after AmB administration.

\section{Acknowledgments}

This work was supported by Kidney and Urologic Research Center Grant DK 39255. Dr. Campbell was the recipient of a Porter Fellowship from the American Physiological Society during this study. Dr. Weihprecht was funded by a Fellowship from the Michigan Affiliate of the American Heart Association. Support for Dr. Lorenz comes from Individual National Research Service Award DK-08411.

\section{References}

1. Butler, W. T., J. E. Bennet, D. W. Alling, P. T. Wertlake, J. P. Utz, and G. J. Hill. 1964. Nephrotoxicity of amphotericin B: early and late effects in 81 patients. Ann. Intern. Med. 61:175-187.

2. Rhodes, E. G., H. E. Ginn, H. G. Muchmore, W. O. Smith, and J. F. Hammersten. 1961. Effects of amphotericin B upon renal function in man. In Antimicrobiology Agents Annual. P. Gray, B. Tabenkin, and S. G. Bradley, editors. Plenum Press, New York. 539-542.

3. McCurdy, D. K., M. Frederic, and J. R. Elkinton. 1968. Renal tubular acidosis due to amphotericin B. N. Engl. J. Med. 278:124-131.

4. Steinmetz, P. R., and L. R. Lawson. 1971. Effect of luminal pH on ion permeability and flows of $\mathrm{Na}^{+}$and $\mathrm{H}^{+}$in turtle bladder. Am. J. Physiol. 220:1573-1580.

5. Gouge, T. H., and V. T. Andreole. 1971. An experimental model of amphotericin B nephrotoxicity with renal tubular acidosis. 1971. J. Lab. Clin. Med. 78:713-724.

6. Bell, N. H., V. T. Andreole, S. M. Sabesin, and J. P. Utz. 1962. On the nephrotoxicity of amphotericin B in man. Am. J. Med. 33:64-69.

7. Butler, W. T., G. J. Hill, C. F. Szwed, and V. Knight. 1964. Amphotericin B renal toxicity in the dog. J. Pharmacol. Exp. Ther. 143:47-56.

8. Tolins, J. P., and L. Raij. 1988. Adverse effect of amphotericin B administration on renal hemodynamics in the rat: neurohumoral mechanisms and influence of calcium channel blockade. J. Pharmacol. Exp. Ther. 245:594-599.

9. Cheng, J.-T., R. T. Witty, R. R. Robinson, and W. E. Yarger. 1982. Amphotericin $B$ nephrotoxicity: increased renal resistance and tubule permeability. Kidney Int. 22:626-633.

10. Iovine G., L. B. Berman, D. N. Halikis, F. H. Mowrey, E. H. Chappelle, and H. W. Gierson. Nephrotoxicity of amphotericin B: a clinical-pathologic study. 1963. Arch. Intern. Med. 112:91-100.

11. Gerkens, J. F., and R. A. Branch. 1980. The influence of sodium status and furosemide on canine acute amphotericin B nephrotoxicity. J. Pharmacol. Exp. Ther. 214:306-311.

12. Schnermann, J, and J. Briggs. 1985 . Function of the juxtaglomerular apparatus: local control of glomerular hemodynamics. In The Kidney: Physiology and Pathophysiology. D. W. Seldin and G. Giebisch, editors. Raven Press, New York. 669-697.

13. Andreoli, T. E., and M. Monahan. 1968. The interaction of polyene antibiotics with thin lipid membranes. J. Gen. Physiol. 52:300-325.

14. Capasso, G. H. Schuetz, B. Vickermann, and R. Kinne. 1986. Amphotericin B and amphotericin B methylester: effect on brush border membrane permeability. Kidney Int. 30:311-317.

15. Persson, A. E. G., J. Schnermann, and F. S. Wright. 1979. Modification of feedback influence on glomerular filtration rate by acute isotonic extracellula volume expansion. Pflügers Arch. Eur. J. Physiol. 381:99-105.
16. Wright, F. S., and J. Schnermann. 1974. Interference with feedback control of glomerular filtration rate by furosemide, triflocin and cyanide. J. Clin. Invest. 53:1695-1708.

17. Osswald, H., G. Nabakowski, and H. Hermes. 1980. Adenosine as a possible mediator of metabolic control of glomerular filtration rate. Int. J. Biochem. 12:263-267.

18. Gerkens, J. F., H. T. Heidemann, E. K. Jackson, and R. A. Branch. 1983. Effect of aminophylline on amphotericin B nephrotoxicity in the dog. J. Pharma col. Exp. Ther. 224:609-613.

19. Heidemann, H. T. J. F. Gerkens, E. K. Jackson, and R. A. Branch. 1983. Effect of aminophylline on renal vasoconstriction produced by amphotericin $B$ in the rat. Arch. Pharmacol. 324:148-152.

20. Müller-Suur, R., H.-U. Gutsche, and H. J. Schurek. 1977. Acute and reversible inhibition of tubuloglomerular feedback mediated afferent vasoconstriction by calcium-antagonist verapamil. In Renal Metabolism in Relation to Renal Function. Schmidt, U., and U. Dubach, editors. Curr. Probl. Clin. Biochem. 6:291-298.

21. Schnermann, J., and J. P. Briggs. 1989. Interaction between loop of Henle flow and arterial pressure as determinants of glomerular pressure. Am. J. Physiol. 256:F421-F429.

22. Greger, R., and W. Hampel. 1981. A modified system for in vitro perfusion of isolated renal tubules. Pflügers Arch. Eur. J. Physiol. 389:175-176.

23. Snedecor, G. W., and W. G. Cochran. 1967. Statistical Methods. Iowa State University Press, Ames, IA.

24. Sabra, R., K. Takahashi, R. A. Branch, and K. Badr. 1990. Mechanism of amphotericin B-induced reduction of the glomerular filtration rate: a micropuncture study. J. Pharmacol. Exp. Ther. 253:34-37.

25. Tolins, J. P., and R. L. Raij. 1988. Chronic amphotericin B nephrotoxicity in the rat, protective effect of prophylactic salt loading. Am. J. Kidney Dis. 11:313-317.

26. Bullock, W. E., R. G. Luke, C. E. Nuttall, and D. Bhathena. 1976. Can mannitol reduce amphotericin B nephrotoxicity? Double-blinded study and description of a new vascular lesion in kidneys. Antimicrob. Agents Chemother. 10:555-563.

27. Reiner, N. E., and W. L. Thompson. 1979. Dopamine and saralasin antagonism of renal vasoconstriction and oliguria caused by amphotericin B in dogs. $J$. Infect. Dis. 140:564-575.

28. Fields, B. T., J. H. Bates, and R. S. Abernathy. 1970. amphotericin B serum concentrations during therapy. Appl. Microbiol. 19:955-959.

29. Ramos, H., A. A. de Murciano, B. E. Cohen, and J. Bolard. 1989. The polyene antibiotic amphotericin $\mathrm{B}$ acts as $\mathrm{Ca} 2+$ ionophore in sterol-containing liposomes. Biochim. Biophys. Acta. 982:303-306.

30. Deuticke, B., M. Kim, and C. Zöllner. 1973. The influence of amphotericin B on the permeability of mammalian erythrocytes to nonelectrolytes, anions and cations. Biochim. Biophys. Acta. 318:345-359.

31. Coulombe, A., O. F. Schanne, I. Reisin, and E. Ruiz-Cretti. 1980. Effects of amphotericin B on electrical properties and electrolyte content of frog sartorius muscle. Can. J. Physiol. Pharmacol. 58: 1138-1141.

32. Reuss, L. 1978. Effects of amphotericin B on the electrical properties of Necturus gallbladder: intracellular microelectrode studies. J. Membr. Biol. 41:65-86.

33. Hosey, M. M., and M. Lazdunski. 1988. Calcium channels: molecular pharmacology, structure and regulation. J. Membr. Biol. 104:81-105.

34. Helman, S. I., W. Nagel, and R. S. Fisher. 1979. Ouabain on active transepithelial sodium transport in frog skin. J. Gen. Physiol. 74:105-127.

35. Schramm, M., G. Thomas, R. Towart, and G. Franckowiak. 1883. Nove dihydropyridines with positive inotropic action through activation of $\mathrm{Ca}^{2+}$ channels. Nature (Lond.). 303:535-537.

36. Loutzenhiser, R., U. T. Rüegg, A. Hof, and R. P. Hof. 1984. Studies on the mechanism of action of the vasoconstrictor dihydropyridine, CGP 28392. Eur. J. Pharmacol. 105:229-237.

37. Thomas, G., M. Chung, and C. J. Cohen. 1985. A dihydropyridine (Bay k 8644) that enhances calcium currents in Guinea pig and calf myocardial cells. Circ. Res. 56:87-96.

38. Deth, R. C., R. A. Payne, and D. M. Peecher. 1987. Influence of furosemide on rubidium- 86 uptake and alpha-adrenergic responsiveness of atrial smooth muscle. Blood Vessels. 24:321-333.

39. Mukherjee, S. K., M. A. Katz, U. F. Michael, and D. A. Ogden. 1981. Mechanisms of hemodynamic actions of furosemide: differentiation of vascular and renal effects on blood pressure in functionally anephric hypertensive patients. Am. Heart J. 101:313-318. 